\title{
Disparities in Guideline-Concordant Initial Systemic Treatment in Women with HER2-Negative Metastatic Breast Cancer: A SEER-Medicare Analysis
}

This article was published in the following Dove Press journal:

Breast Cancer: Targets and Therapy

\author{
Ami Vyas' \\ Meghan Gabriel ${ }^{2}$ \\ Sobha Kurian ${ }^{3}$ \\ 'Department of Pharmacy Practice, \\ College of Pharmacy, University of Rhode \\ Island, Kingston, RI, USA; ${ }^{2}$ Pharmacy \\ Quality Alliance, Alexandria, VA, USA; \\ ${ }^{3}$ West Virginia University, School of \\ Medicine, Morgantown, WV, USA
}

Background: Data on guideline-concordant initial systemic treatment among women with HER2-negative metastatic breast cancer (MBC) are limited. We determined the proportion of women with HER2-negative MBC who received guideline-concordant treatment and the extent to which independent variables explained differences in guideline-concordant treatment by hormone receptor (HR) status.

Methods: We conducted a retrospective cohort study using the SEER-Medicare database. We included women age $>65$ years diagnosed with HER2-negative MBC during 2010-2013. We used the National Comprehensive Cancer Network treatment guidelines to determine guideline-concordant initial treatment within the first 6 months of a cancer diagnosis. We conducted a multivariable logistic regression to identify the significant predictors of guideline-concordant treatment and a non-linear decomposition method to examine disparities by HR status.

Results: Among 1089 eligible women, 72.3\% received guideline-concordant treatment. Compared to women who did not receive guideline-concordant treatment, women who received guideline-concordant treatment were more like to be comparatively older $(p<0.05)$, married $(p=0.0171)$, resided in areas with higher proportion of people age $\geq 25$ years with at least four years of college education, and had positive HR status $(p<0.0001)$. Approximately $8 \%$ of the disparity in guideline-concordant treatment by HR status was explained by their observed characteristics. Need-related factors explained the highest proportion $(66.9 \%)$ of the disparity.

Conclusion: Our findings indicate improvement of care for older women, who are single/ divorced, have negative HR status, and who live in area with lower education levels. Unexplained disparities in guideline-concordant treatment by HR status can be attributed to patient preferences for treatment, physician-level factors, and perceptions.

Keywords: guideline-concordant treatment, decomposition, HER2-negative, breast cancer, SEER-Medicare database

\section{Introduction}

Metastatic breast cancer (MBC) occurs in 6-10\% of newly diagnosed cases. ${ }^{1}$ Overall survival of women with $\mathrm{MBC}$ can range from a few months to a few years depending on the molecular subtype, ${ }^{2,3}$ with almost none cured. More than $80 \%$ of the MBC cases are human epidermal growth factor receptor 2 (HER2)-negative tumors characterized by similar to poorer survival than those with HER2 positive tumors. ${ }^{4}$
Correspondence: Ami Vyas College of Pharmacy, University of Rhode Island, 7 Greenhouse Road, Kingston, RI, 0288I, USA

Tel + I-40I-874-7255

Fax +I-40I-874-27I7

Email avyas@uri.edu
Breast Cancer: Targets and Therapy 2021:13 259-269 
Prognosis has improved substantially for HER2-positive MBC because of the introduction of HER2 targeted therapies but has lagged for HER2-negative cases as development of new targeted therapies for HER2-negative cancers is only commencing. ${ }^{5}$

Providing cancer care per recommended treatment guidelines can help improve patient health outcomes; however, not all the patients with $\mathrm{BC}$ receive guidelineconcordant cancer treatment. ${ }^{6,7}$ The National Comprehensive Cancer Network (NCCN) BC treatment guidelines recommend the use of chemotherapy and/or endocrine therapy for HER2-negative $\mathrm{MBC}^{8}{ }^{8}$ A large body of literature about guideline-concordant cancer care exist for early-stage BC cases. However, to date, very few real-world US studies have investigated guidelineconcordant cancer treatment and identified opportunities to improve cancer care among women with MBC. ${ }^{6,9}$ Still, the literature regarding $\mathrm{MBC}$, particularly in patients with HER2-negative cancers, is extremely limited. ${ }^{10}$ A study by Poorvu et al was conducted using the SEER-Medicare data for women diagnosed with MBC during 2010-2011 and reported that $24 \%$ of HER2-negative patients did not receive any systemic therapy in the first 6 months following cancer diagnosis. ${ }^{9}$ However, the predictors of guideline-concordant care among HER2-negative cases were not identified in the study. Another study also used the SEER-Medicare data for women diagnosed with MBC during 2007-2013 and reported that 12\% of HER2negative cases did not receive guideline-concordant care, ${ }^{6}$ but did not specifically identify factors that influence guideline-concordant care in HER2-negative cases. Additionally, performance status, a vital factor that impacts treatment decision in patients with advanced cancer, ${ }^{11}$ was not accessed in these studies.

Hence, it is critical to examine if women with HER2-negative MBC are treated as per the guidelines, and the predictors of guideline-concordant treatment, especially in women age 65 and older who have higher cancer burden and poorer outcomes. ${ }^{12}$ The goal of this study was to determine if women age 65 and above with HER2-negative MBC were treated as per the established treatment guidelines and to identify the factors that impact the guideline-concordant treatment. We also used a non-linear decomposition method to examine the magnitude of disparities in guideline-concordant treatment by hormone receptor (HR) status as a posthoc objective.

\section{Methods}

\section{Study Design and Data Source}

We used the SEER-Medicare linked dataset to conduct a retrospective observational cohort study. The SEER program provides data on newly diagnosed cancer cases from 18 population-based tumor registries that obtain data from hospitals, outpatient clinics, laboratories, private practitioners, laboratories, hospices, autopsy reports, and death certificates. The SEER program covers $26 \%$ of the US population with cancer. ${ }^{13}$ The Medicare files provide data on the use of inpatient, outpatient, physician, home health, durable medical equipment, and hospice care by individuals age 65 and above enrolled in CMS Medicare program. We linked the SEER cancer cases to the Medicare claims files. ${ }^{14}$ The details of the SEER-Medicare dataset are reported elsewhere. ${ }^{13}$ We linked the Area Health Resource File (AHRF) to the SEER-Medicare dataset to obtain the census level data on median household income, education, and number of hospitals offering oncology services. ${ }^{15}$

\section{Study Cohort}

We included women aged 66 and above at the diagnosis of first pathologically confirmed metastatic $\mathrm{BC}^{15}$ during 2010-2013 with HER2-negative status. Women diagnosed via a death certificate or autopsy were excluded. Additionally, we excluded women who were enrolled in health maintenance organizations, who were not continuously enrolled in Medicare parts A and B for 12 months before cancer diagnosis through at least 6 months following diagnosis or death, and who were not continuously enrolled in Medicare part D for at least 6 months following diagnosis or death, whichever occurred first.

\section{Measures}

Dependent Variable: Guideline-Concordant Initial Systemic Breast Cancer Treatment

The data on HER2 status are available in SEER for BC cases diagnosed from 2010 onwards. Tumor status was determined using the information for HER2 status along with HR status. The NCCN guidelines for HER2-negative MBC were used to determine receipt of guidelineconcordant initial systemic treatment within 6 months following cancer diagnosis as per the woman's tumor status (Supplemental Table 1). All the versions of the NCCN guidelines published during 2010-2013 were used to identify initial treatment strategies. ${ }^{8,16-19}$ If a woman 
received a treatment regimen that matched a systemic treatment regimen provided in the NCCN guidelines (Supplemental Table 1) per the tumor status then she was considered to have obtained guideline-concordant treatment. We identified endocrine therapies and infused or oral chemotherapies from the Medicare claims using J-codes and National Drug Codes.

We grouped our study cohort into those who received guideline-concordant initial systemic treatment and those who did not receive guideline-concordant initial systemic treatment.

\section{Explanatory Variables}

We used the Andersen behavioral model of healthcare services utilization to identify the significant predictors of guideline-concordant treatment. ${ }^{20,21}$ As per this model, healthcare utilization depends on the predisposition of individuals to use medical services, factors that enable or impede use, the need for care, healthcare use, and external healthcare environmental factors. Predisposing characteristics comprised age at cancer diagnosis and race/ethnicity, while enabling characteristics included marital status, census tract median household income, and census tract percentage of people age $\geq 25$ years with at least 4 years of college education. Need-related factors included HR status, grade of tumor, comorbidity scores, performance status proxies, and the number of sites with cancer metastasis. We used data about co-occurring chronic conditions occurring within 12 months before $\mathrm{BC}$ diagnosis $^{22-24}$ to obtain comorbidity scores. In addition, we identified claims associated with hospitalization, use of skilled nursing facility, oxygen use and related supplies, and use of wheelchair and walking aids, in the year prior to cancer diagnosis, to develop a proxy for performance status. ${ }^{25}$ Healthcare use was determined by medical oncology office visits ${ }^{26}$ in the follow-up period. External healthcare environmental factors comprised the location of residence, SEER region, and census level information on the number of hospitals offering oncology services.

\section{Statistical Analyses}

Descriptive statistics and Chi-square tests were conducted to describe the study cohort and to identify significant differences by receipt of guideline-concordant treatment. Multivariable logistic regression was used to identify significant predictors of guideline-concordant treatment in women with HER2-negative MBC.
HER2 status and HR status are important indicators for guiding $\mathrm{BC}$ care. ${ }^{17}$ Additionally, studies have indicated HR status as a crucial predictor of guideline-concordant BC care. ${ }^{6,9}$ Furthermore, survival is significantly different for HER2-negative patients with positive and negative HR status. Triple-negative MBC patients have poorer survival compared to patients with HER2-/HR+ $\mathrm{MBC},{ }^{27}$ and women with triple-negative MBC are treated with aggressive cytotoxic chemotherapy regimens. A post-regression non-linear decomposition technique ${ }^{28}$ was performed to quantify the disparities in guideline-concordant treatment by woman's HR status, and also to identify the extent to which explanatory variables (excluding HR status) explained these disparities. The disparity in treatment by HR status is grouped into two portions: the "explained" portion which is due to differences in the explanatory variables between two groups and the "unexplained" portion captures differences in the regression parameter estimates between two groups or differences in unobservable or unmeasured parameters (provider level, organizational level characteristics). The explained portion of the disparity by HR status is the sum of the differences between HRpositive and HR-negative women in terms of the observed characteristics weighted by the pooled regression coefficients.

All analyses were conducted within statistical analysis system software SAS version 9.4 (SAS Institute Inc., Cary, NC, USA) and STATA version 15.0 (StataCorp LLC).

\section{Results \\ Descriptive Characteristics}

After applying the inclusion-exclusion criteria, 1089 women aged 66 and older diagnosed with first HER2negative MBC during 2010-2013 were identified and included in the study (Figure 1). The left columns in Table 1 describe the study cohort, while the right columns in Table 1 provide information on the study cohort by the receipt of guideline-concordat treatments and nonguideline-concordant treatment. Fifty-seven percent were aged 75 and older, $85.1 \%$ were White, $70.8 \%$ were single or divorced or widowed, $84.7 \%$ resided in metro regions, $82.7 \%$ had HR-positive tumor, $45.3 \%$ had well or moderately differentiated tumor, $73.8 \%$ had good performance status, and $60.6 \%$ had at least one comorbidity (Table 1 ).

About $72.3 \%$ received guideline-concordant treatment as per the NCCN guidelines and $27.7 \%$ did not. Women who received guideline-concordant treatment were 
Patients diagnosed with initial de novo metastatic breast cancer between January 2010 and December $2013(\mathrm{~N}=7,470)$

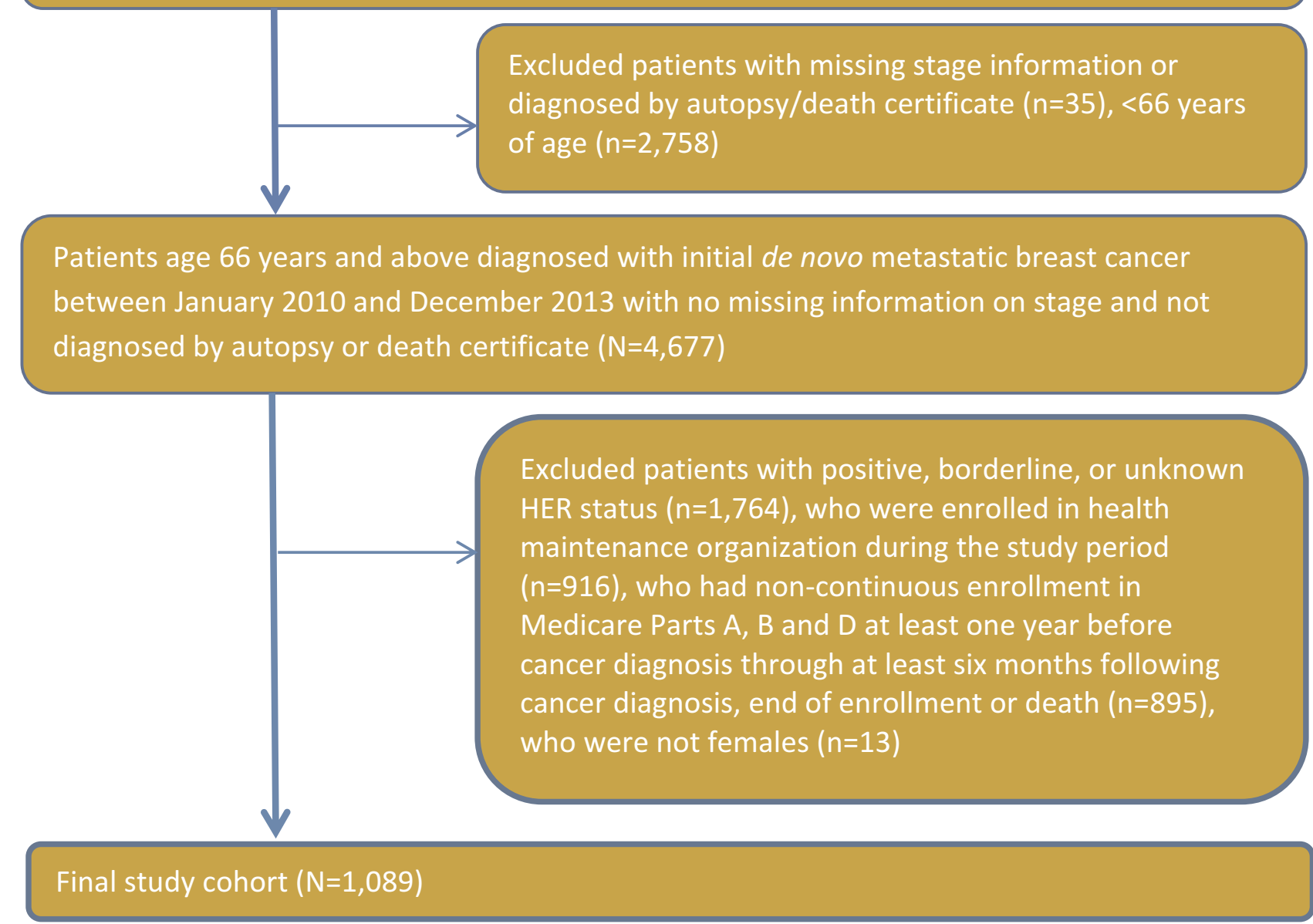

Figure I Patient flow diagram.

significantly more likely to be age 66-69 years, married or partnered, lived in non-metro areas, had positive HR status, had a well or moderately differentiated grade tumor, had good performance status, had no comorbidity, and had a higher number of medical oncology visits.

Among patients with HR-positive MBC who received guideline-concordant care, $76.2 \%$ received endocrine therapy only, $12.3 \%$ received both endocrine therapy and chemotherapy, while $11.5 \%$ received chemotherapy only. While among those who did not receive guideline-concordant care, all of them did not receive either chemotherapy or endocrine therapy. Among patients with HR-negative MBC who received guideline-concordant care, all of them received chemotherapy. While among those who did not receive guideline-concordant care, $85.7 \%$ received no treatment and $14.3 \%$ received endocrine therapy.

\section{Predictors of Guideline-Concordant Treatment}

Women age 70 years of age and older with HER2-negative MBC were significantly less likely to receive guidelineconcordant treatment compared to those 66-69 years of age (Table 2). The adjusted odds ratios (AOR) for women in the age groups 70-74, 75-59, and age 80 and above were $0.581(95 \%$ confidence interval $(\mathrm{CI})=0.352-0.960$, $\mathrm{p}=0.0339), 0.593(95 \% \mathrm{CI}=0.355-0.990, \mathrm{p}=0.0456)$, and $0.410(95 \% \mathrm{CI}=0.259-0.651, \mathrm{p}=0.0002)$, respectively (Table 2). Women whose annual household income was $>\$ 60,000$ were $51 \%$ less likely to receive guidelineconcordant treatment compared to those with an annual household income of $\leq \$ 45,000$. Compared to women who were single or widowed or divorced, those who were 
Table I Description of Medicare FFS Beneficiaries with Metastatic HER2-Negative Breast Cancer by Receipt of Guideline-Concordant Initial Systemic Treatment SEER-Medicare 2010-2013 Cases

\begin{tabular}{|c|c|c|c|c|c|c|c|}
\hline \multirow[t]{2}{*}{ Variables } & \multicolumn{2}{|c|}{ Total Cohort } & \multicolumn{2}{|c|}{$\begin{array}{c}\text { Guideline-Concordant } \\
\text { Treatment }\end{array}$} & \multicolumn{2}{|c|}{$\begin{array}{c}\text { Non-Guideline-Concordant } \\
\text { Treatment }\end{array}$} & \multirow[t]{2}{*}{ p-value } \\
\hline & $N=1089$ & $\%$ & $N=787(72.3 \%)$ & $\%$ & $N=302(27.7 \%)$ & $\%$ & \\
\hline Age at Diagnosis & & & & & & & $<0.0001$ \\
\hline $66-69$ & 203 & $18.6 \%$ & 169 & $83.3 \%$ & 34 & $16.7 \%$ & \\
\hline $70-74$ & 266 & $24.4 \%$ & 202 & $75.9 \%$ & 64 & $24.1 \%$ & \\
\hline $75-79$ & 225 & $20.7 \%$ & 168 & $74.7 \%$ & 57 & $25.3 \%$ & \\
\hline $80+$ & 395 & $36.3 \%$ & 248 & $62.8 \%$ & 147 & $37.2 \%$ & \\
\hline Race/Ethnicity & & & & & & & 0.8381 \\
\hline Whites & 927 & $85.1 \%$ & 671 & $72.4 \%$ & 256 & $27.6 \%$ & \\
\hline Others & 162 & $14.9 \%$ & 116 & $71.6 \%$ & 46 & $28.4 \%$ & \\
\hline Marital Status & & & & & & & 0.0010 \\
\hline Married/Partnered & 318 & $29.2 \%$ & 252 & $79.3 \%$ & 66 & $20.7 \%$ & \\
\hline Single/Divorced/Widowed & 771 & $70.8 \%$ & 535 & $69.4 \%$ & 236 & $30.6 \%$ & \\
\hline Location of Residence & & & & & & & 0.0336 \\
\hline Metro & 922 & $84.7 \%$ & 655 & $71.0 \%$ & 267 & $29.0 \%$ & \\
\hline Non-metro & 167 & $15.3 \%$ & 132 & $79.0 \%$ & 35 & $21.0 \%$ & \\
\hline SEER Region & & & & & & & 0.2950 \\
\hline North East & 284 & $26.1 \%$ & 199 & $70.1 \%$ & 85 & $29.9 \%$ & \\
\hline South & 266 & $24.4 \%$ & 198 & $74.4 \%$ & 68 & $25.6 \%$ & \\
\hline North Central & 158 & $14.5 \%$ & 107 & $67.7 \%$ & 51 & $32.3 \%$ & \\
\hline West & 381 & $35.0 \%$ & 283 & $74.3 \%$ & 98 & $25.7 \%$ & \\
\hline Census Tract Household Income & & & & & & & 0.5412 \\
\hline LE $\$ 45,000$ & 237 & $21.8 \%$ & 177 & $74.7 \%$ & 60 & $25.3 \%$ & \\
\hline$\$ 45,001-\$ 60,000$ & 369 & $33.9 \%$ & 268 & $72.6 \%$ & 101 & $27.4 \%$ & \\
\hline GT $\$ 60,000$ & 483 & $44.5 \%$ & 342 & $70.8 \%$ & 141 & $29.2 \%$ & \\
\hline Census Tract Education & & & & & & & 0.9947 \\
\hline $0-22.0$ & 300 & $27.6 \%$ & 217 & $72.3 \%$ & 83 & $27.7 \%$ & \\
\hline $22.1-30.3$ & 278 & $25.5 \%$ & 201 & $72.3 \%$ & 77 & $27.7 \%$ & \\
\hline $30.4-37.7$ & 247 & $22.7 \%$ & 177 & $71.7 \%$ & 70 & $28.3 \%$ & \\
\hline GT 37.7 & 264 & $24.2 \%$ & 192 & $72.7 \%$ & 72 & $27.3 \%$ & \\
\hline Hormone Receptor Status & & & & & & & $<0.0001$ \\
\hline Positive & 901 & $82.7 \%$ & 697 & $77.4 \%$ & 204 & $22.6 \%$ & \\
\hline Negative & 188 & $17.3 \%$ & 90 & $47.9 \%$ & 98 & $52.1 \%$ & \\
\hline Grade of Tumor & & & & & & & 0.0038 \\
\hline Well/Moderately differentiated & 493 & $45.3 \%$ & 375 & $76.1 \%$ & 118 & $23.9 \%$ & \\
\hline Poorly/Very poorly differentiated & 361 & $33.1 \%$ & 238 & $65.9 \%$ & 123 & $34.1 \%$ & \\
\hline Unknown & 235 & $21.6 \%$ & 174 & $74.0 \%$ & 61 & $26.0 \%$ & \\
\hline Number of Metastatic Sites* & & & & & & & 0.9633 \\
\hline $0-1$ & 785 & $72.1 \%$ & 567 & $72.2 \%$ & 218 & $27.8 \%$ & \\
\hline $2-4$ & 304 & $27.9 \%$ & 220 & $72.4 \%$ & 84 & $27.6 \%$ & \\
\hline Performance Status & & & & & & & 0.0212 \\
\hline Good & 804 & $73.8 \%$ & 596 & $74.1 \%$ & 208 & $25.9 \%$ & \\
\hline Poor & 285 & $26.2 \%$ & 191 & $67.0 \%$ & 94 & $33.0 \%$ & \\
\hline
\end{tabular}

(Continued) 
Table I (Continued).

\begin{tabular}{|c|c|c|c|c|c|c|c|}
\hline \multirow[t]{2}{*}{ Variables } & \multicolumn{2}{|c|}{ Total Cohort } & \multicolumn{2}{|c|}{$\begin{array}{c}\text { Guideline-Concordant } \\
\text { Treatment }\end{array}$} & \multicolumn{2}{|c|}{$\begin{array}{c}\text { Non-Guideline-Concordant } \\
\text { Treatment }\end{array}$} & \multirow[t]{2}{*}{ p-value } \\
\hline & $N=1089$ & $\%$ & $N=787(72.3 \%)$ & $\%$ & $N=302(27.7 \%)$ & $\%$ & \\
\hline Comorbidity & & & & & & & 0.0206 \\
\hline 0 & 429 & $39.4 \%$ & 325 & $75.8 \%$ & 104 & $24.2 \%$ & \\
\hline 1 & 241 & $22.1 \%$ & 179 & $74.3 \%$ & 62 & $25.7 \%$ & \\
\hline $2+$ & 419 & $38.5 \%$ & 283 & $67.5 \%$ & 136 & $32.5 \%$ & \\
\hline Oncology Visits & & & & & & & $<0.0001$ \\
\hline $0-8$ & 368 & $33.8 \%$ & 215 & $58.4 \%$ & 153 & $41.6 \%$ & \\
\hline $9-25$ & 323 & $29.7 \%$ & 226 & $70.0 \%$ & 97 & $30.0 \%$ & \\
\hline GT 25 & 398 & $36.5 \%$ & 346 & $86.9 \%$ & 52 & $13.7 \%$ & \\
\hline Hospitals Offering Oncology Services & & & & & & & 0.6072 \\
\hline $0-1$ & 361 & $33.2 \%$ & 270 & $74.8 \%$ & 91 & $25.2 \%$ & \\
\hline $2-3$ & 228 & $20.9 \%$ & 160 & $70.2 \%$ & 68 & $29.8 \%$ & \\
\hline $4-6$ & 263 & $24.2 \%$ & 188 & $71.5 \%$ & 75 & $28.5 \%$ & \\
\hline GT 6 & 237 & $21.7 \%$ & 169 & $71.3 \%$ & 68 & $28.7 \%$ & \\
\hline
\end{tabular}

Note: *Number of metastatic sites refers to metastasis to brain, liver, lung, or bone.

Abbreviations: FFS, fee for service; LE, less than or equal to; GT, greater than.

married or partnered were $53 \%$ more likely to receive guideline-concordant treatment $(\mathrm{AOR}=1.528,95 \%$ $\mathrm{CI}=1.079-2.164, \mathrm{p}=0.0171)$. Women with triple-negative MBC were significantly less likely to receive guidelineconcordant treatment compared to women diagnosed with HR-positive tumor $(\mathrm{AOR}=0.250 ; 95 \% \mathrm{CI}=0.171-0.366$, $\mathrm{p}<0.0001)$. Women who had higher medical oncology office visits were significantly more likely to receive guideline-concordant treatment compared to those with lower medical oncology office visits.

\section{Decomposition Analysis by Hormone Receptor Status}

The percentage-point-difference in the proportion of women who received guideline-concordant treatment by their HR status was 29.5 (Table 3). By decomposing this difference, out of a 29.5-percentage-point difference, a 2.22-percentage point difference was explained by the observed characteristics, which represents $7.52 \%$ of the total disparity in guideline-concordant treatment between women with positive and negative HR status. Need-related factors explained the highest proportion $(66.89 \%)$ of the disparity. This was followed by healthcare use factors at $55.72 \%$, external healthcare environmental factors at $9.31 \%$, predisposing factors at $3.19 \%$, and enabling factors at $-35.11 \%$. The findings of need-related factors can be interpreted as: if women with positive and negative HR status were similar in terms of their need-related factors, then the disparity in guideline-concordant treatment would decrease by $66.89 \%$. The negative value for enabling characteristics suggests that if enabling factors of two groups of women were alike, then the disparity will increase by $35.11 \%$. Over ninety percent $(92.48 \%)$ of the difference in guideline-concordant treatment by HR status remained unexplained.

\section{Discussion}

To our knowledge, this is the first study that examined guideline-concordant initial systemic treatment among women age 65 and older with HER2-negative MBC and its predictors after controlling for several confounders, including performance status. We also discovered some insights into the magnitude of disparities in guideline-concordant treatment by women's HR status using an advanced non-linear decomposition method. Approximately $72 \%$ of the study cohort with HER2negative $\mathrm{MBC}$ received NCCN guideline-concordant initial systemic treatment. Also, $77.4 \%$ of women with HR-positive tumors and $47.9 \%$ with HR-negative tumors received guideline-concordant care. The overall estimate is lower than that reported previously for HER2negative MBC cases $(72 \% \text { vs } 88 \%)^{6}$ but somewhat 
Table 2 Adjusted Odds Ratios and 95\% Confidence Intervals from Logistic Regression on Guideline-Concordant Initial Systemic Treatment Among Medicare FFS Beneficiaries with Metastatic HER2-Negative Breast Cancer SEER-Medicare 2010-2013 Cases

\begin{tabular}{|c|c|c|c|}
\hline \multirow[t]{2}{*}{ Variables } & \multicolumn{3}{|c|}{ Guideline-Concordant Care } \\
\hline & AOR & $95 \% \mathrm{Cl}$ & p-value \\
\hline \multicolumn{4}{|l|}{ Age at Diagnosis } \\
\hline $66-69$ & Reference & & \\
\hline $70-74$ & $0.58 \mathrm{I}$ & {$[0.352,0.960]$} & 0.0339 \\
\hline $75-79$ & 0.593 & {$[0.355,0.990]$} & 0.0456 \\
\hline $80+$ & 0.410 & {$[0.259,0.651]$} & 0.0002 \\
\hline \multicolumn{4}{|l|}{ Race/Ethnicity } \\
\hline White & Reference & & \\
\hline Others & 1.395 & {$[0.989,2.169]$} & 0.1388 \\
\hline \multicolumn{4}{|l|}{ Location of Residence } \\
\hline Metro & Reference & & \\
\hline Non-metro & 1.537 & {$[0.945,2.500]$} & 0.0834 \\
\hline \multicolumn{4}{|l|}{ Census Tract Household Income } \\
\hline LE $\$ 45,000$ & Reference & & \\
\hline$\$ 45,00 \mathrm{I}-\$ 60,000$ & 0.679 & {$[0.426,1.081]$} & 0.1027 \\
\hline GT $\$ 60,000$ & 0.487 & {$[0.265,0.894]$} & 0.0203 \\
\hline \multicolumn{4}{|l|}{ Census Tract Education } \\
\hline $0-22.0$ & Reference & & \\
\hline $22.1-30.3$ & 1.162 & {$[0.735,1.836]$} & 0.5214 \\
\hline $30.4-37.7$ & 1.570 & {$[0.891,2.767]$} & 0.1190 \\
\hline GT 37.7 & 2.058 & {$[1.111,3.810]$} & 0.0217 \\
\hline \multicolumn{4}{|l|}{ Marital Status } \\
\hline Married/Partnered & 1.528 & {$[1.079,2.164]$} & 0.0171 \\
\hline Single/Divorced/Widowed & Reference & & \\
\hline \multicolumn{4}{|l|}{ Hormone Receptor Status } \\
\hline Positive & Reference & & \\
\hline Negative & 0.250 & {$[0.171,0.366]$} & $<0.0001$ \\
\hline \multicolumn{4}{|l|}{ Grade of Tumor } \\
\hline Well/Moderately differentiated & Reference & & \\
\hline Poorly/Very poorly differentiated & 0.724 & {$[0.510,1.026]$} & 0.0697 \\
\hline Unknown & 0.886 & {$[0.598,1.312]$} & 0.5447 \\
\hline \multicolumn{4}{|l|}{ Oncology Visits } \\
\hline $0-8$ & Reference & & \\
\hline $9-25$ & 1.592 & {$[1.136,2.233]$} & 0.0070 \\
\hline GT 25 & 4.868 & {$[3.292,7.197]$} & $<0.0001$ \\
\hline
\end{tabular}

Abbreviations: GT, greater than; LE, less than equal to; $A O R$, adjusted odds ratio; $\mathrm{Cl}$, confidence interval.

similar to that found in another study ( $72 \%$ vs $76 \%$ ), and also by type of HR status. ${ }^{9,29}$ More than a quarter of the study cohort with HER2-negative MBC and more than half with triple-negative $\mathrm{MBC}$ did not receive initial guideline-recommended cancer treatment, which indicates several opportunities for the improvement of cancer care.
Age at cancer diagnosis, a predisposing factor, significantly predicted receipt of guideline-concordant treatment in women age 65 and above with HER2-negative MBC. The adjusted odds ratios of the receipt of guidelineconcordant care decreased with an increase in age, a finding consistent with that published earlier. ${ }^{9}$ Perhaps, with increase in age, women age 65 and above may be less 
Table 3 Nonlinear Decomposition of Guideline-Concordant Initial Systemic Treatment Among Medicare FFS Beneficiaries with Metastatic HER2-Negative Breast Cancer with Positive and Negative Hormone Receptor Status SEER-Medicare 2010-2013 Cases

\begin{tabular}{|c|c|c|}
\hline \multirow[b]{2}{*}{$\begin{array}{l}\% \text { of HR-positive cases with } \\
\text { guideline-concordant care }\end{array}$} & \multicolumn{2}{|c|}{$\begin{array}{c}\text { Guideline-Concordant } \\
\text { Treatment }\end{array}$} \\
\hline & $77.4 \%$ & \\
\hline $\begin{array}{l}\% \text { of HR-negative cases with } \\
\text { guideline-concordant care }\end{array}$ & $47.9 \%$ & \\
\hline Difference & 29.5 & \\
\hline Total “Explained” (\%) & 2.22 & \\
\hline Variables & $\begin{array}{l}\text { \% of } \\
\text { “Explained" } \\
\text { Difference }\end{array}$ & $\begin{array}{l}\text { \% Contribution } \\
\text { to the } \\
\text { "Explained" } \\
\text { Portion }\end{array}$ \\
\hline $\begin{array}{l}\text { Predisposing factors (Age at } \\
\text { breast cancer diagnosis*, } \\
\text { Race/Ethnicity) }\end{array}$ & $0.24 \%$ & $3.19 \%$ \\
\hline $\begin{array}{l}\text { Enabling factors (Marital } \\
\text { status, Census tract median } \\
\text { household income** and } \\
\text { education*) }\end{array}$ & $-2.64 \%$ & $-35.11 \%$ \\
\hline $\begin{array}{l}\text { Need-related factors } \\
\text { (Grade of tumor*, } \\
\text { Comorbidity, Performance } \\
\text { status, Number of sites of } \\
\text { cancer metastasis) }\end{array}$ & $5.03 \%$ & $66.89 \%$ \\
\hline $\begin{array}{l}\text { Healthcare use (Medical } \\
\text { oncology office visits***) }\end{array}$ & $4.19 \%$ & $55.72 \%$ \\
\hline $\begin{array}{l}\text { External healthcare } \\
\text { environmental factors } \\
\text { (Location of residence, } \\
\text { SEER region, Hospitals } \\
\text { offering oncology services) }\end{array}$ & $0.70 \%$ & $9.31 \%$ \\
\hline Total Difference Explained & $7.52 \%$ & $100 \%$ \\
\hline $\begin{array}{l}\text { Total Difference } \\
\text { Unexplained }\end{array}$ & $92.48 \%$ & \\
\hline
\end{tabular}

Notes: ${ }^{*} p<0.1 ; * * p<0.05$; ${ }^{* *} p<0.001$. We used the $p$-value of $<0.1$ due to relatively smaller sample size of HR-negative cases compared to HR-positive cases.

likely to receive aggressive cancer treatments given their overall health status, which may reduce their likelihood of receiving guideline-concordant initial cancer care. Similar to an earlier study, ${ }^{9}$ we found that an enabling factor, being married or partnered, significantly predicted receipt of guideline-concordant cancer treatment. This suggests that social support may aid in facilitating cancer care.

With regards to need-related factors, women with triple-negative tumors had lower odds of the receipt of guideline-concordant treatment compared to those with HR-positive tumor, adding support to an earlier study. ${ }^{9}$ Over the past two decades, treatment options in triplenegative tumors have been limited to conventional cytotoxic chemotherapy with considerable toxicity, ${ }^{30-32}$ whereas HR-positive patients have multiple options including hormonal therapy which is comparatively less toxic. Hence, due to the lack of effective less-toxic therapies for triple-negative $\mathrm{MBC},{ }^{33,34}$ this older group may be less likely to receive guideline-concordant treatment. However, recent evidence has emerged regarding the efficacy of targeted immune checkpoint inhibitors when combined with chemotherapy as the first-line treatment of triple-negative MBC. ${ }^{35,36}$ With the approval of the combination of chemotherapy and immunotherapy for triplenegative $\mathrm{MBC}$, a higher proportion of women with the disease may receive guideline-concordant care in near future, however, this may not be highly evident in the older group due to drug-related toxicities.

From the decomposition analysis, we found that about $8 \%$ of disparity in guideline-concordant treatment between women with HR-positive and HR-negative tumors was explained by the covariates included in the regression model. Need-related factors which consisted of tumor grade, comorbidities, performance status, and several sites of cancer metastasis contributed the highest portion of explained disparities. Consistent with the previous literature, ${ }^{37}$ we found that a higher percentage of women with HR-negative tumors had poorly, undifferentiated or unknown grade than those with HR-positive tumors (data not shown), which explained 5\% of disparity. This finding signifies that if women with HR-negative tumors had the same tumor grade as women with HR-positive tumors then the disparity may decrease by $5 \%$, thereby indicating opportunities of improvement in women with poor or undifferentiated HR-negative tumors. Additionally, healthcare use in terms of medical oncology office visits contributed to a substantial amount of the disparity in guideline-concordant between the two groups. To our knowledge, no study specifically examined medical oncology office visits in women with HER2-negative MBC. Therefore, it is important that further research explore this finding regarding the ambulatory visits and predicting factors of use among these two cohorts. We also found that 
approximately $92 \%$ of the disparity in guidelineconcordant treatment by women's HR status was unexplained. Some of this unexplained difference may be due to patient's severity of comorbidities, and patient and physician treatment choices that are not available in the database. This is a critical area for further research, as treatment varies by HR status.

This study has a strong conceptual framework and used an advanced decomposition method to identify disparities in guideline-concordant initial treatment by HR status among women with HER2-negative MBC. This study also leveraged SEER-Medicare data to conduct a comprehensive analysis. However, secondary data analyses have inherent limitations. Some limitations of the study include use of census level information on patient's household income, education level, and access to oncology hospitals, ${ }^{38}$ and limited generalizability of the study findings to older BC patients enrolled in Medicare. Additionally, the SEERMedicare does not provide information on patient's severity of comorbidities and patient preferences and physician preferences which may impact treatment choices. However, we controlled for performance status proxy in the analyses. Furthermore, we did not measure any gaps in the treatment after the patients initiated their treatment, which may ultimately affect their clinical outcomes. However, measuring outcomes was not the objective of this study.

\section{Conclusion}

More than a quarter of older women with HER2-negative $\mathrm{MBC}$ did not receive guideline-concordant treatment as per the NCCN treatment guidelines and the non-receipt of guideline-concordant treatment was higher in older women age 70 and above and those with negative hormone receptor status. In decomposition analysis, approximately $8 \%$ of the disparity in guideline-concordant treatment was explained thereby identified opportunities of cancer care improvement for older women, especially with negative HR status.

\section{Data Sharing Statement}

Data sharing not available due to restrictions. The SEERMedicare data needs to be requested for the specific research aims and cannot be shared due to restrictions. The Area Health Resource File is a publicly available database.

\section{Ethical Approval Statement}

Since the study was conducted using a de-identified secondary database, the University of Rhode Island (USA) Institutional Review Board committee considered this study as exempt from human subjects research. The Area Health Resource File data are freely available to the researchers from the website: https://data.hrsa.gov/topics/ health-workforce/ahrf. The researchers need to apply for the SEER-Medicare data to perform the research. More information about the SEER-Medicare data is available on: https://healthcaredelivery.cancer.gov/seermedicare/.

\section{Acknowledgments}

This study was funded by the Rhode Island Foundation Medical Research Funds received by Dr. Vyas. Drs. Gabriel and Kurian have no funding to report. The content is solely the responsibility of the authors and does not necessarily represent the official views of Rhode Island Foundation.

Partial results of these analyses were presented at the following conference: American Association for Cancer Research Annual Meeting 2019, March-April 2019, Atlanta, GA.

\section{Author Contributions}

All authors (AV, MG, SK) made significant contribution to the work reported, whether it is in the conception, study design, execution, acquisition of data, analysis and interpretation, or in all these areas. All the authors equally took part in drafting, revising or critically reviewing the article, provided final approval of the version to be published, have agreed on the journal to which the article has been submitted, and also agree to be accountable for all aspects of the work.

\section{Disclosures}

No conflict of interests or disclosures.

\section{References}

1. Lu J, Steeg PS, Price JE, et al. Breast cancer metastasis: challenges and opportunities. Cancer Res. 2009;69(12):4951-4953. doi:10.1158/ 0008-5472.CAN-09-0099

2. Bonotto M, Gerratana L, Poletto E, et al. Measures of outcome in metastatic breast cancer: insights from a real-world scenario. Oncol. 2014;19(6):608-615. doi:10.1634/theoncologist.2014-0002

3. Kiely BE, Soon YY, Tattersall MHN, Stockler MR. How long have I got? Estimating typical, best-case, and worst-case scenarios for patients starting first-line chemotherapy for metastatic breast cancer: a systematic review of recent randomized trials. J Clin Oncol. 2011;29 (4):456-463. doi:10.1200/JCO.2010.30.2174

4. Press DJ, Miller ME, Liederbach E, Yao K, Huo D. De novo metastasis in breast cancer: occurrence and overall survival stratified by molecular subtype. Clin Exp Metastasis. 2017;34(8):457-465. doi:10.1007/s10585-017-9871-9

5. Partridge AH, Rumble RB, Carey LA, et al. Chemotherapy and targeted therapy for women with human epidermal growth factor receptor 2-negative (or unknown) advanced breast cancer: American Society of clinical oncology clinical practice guideline. J Clin Oncol. 2014;32 (29):3307-3329. doi:10.1200/JCO.2014.56.7479 
6. Rocque GB, Williams CP, Jackson BE, et al. Impact of nonconcordance with NCCN guidelines on resource utilization, costs, and mortality in de novo metastatic breast cancer. J Natl Compr Canc Netw. 2018;16(9):1084-1091. doi:10.6004/jnccn.2018.7036

7. LeMasters T, Madhavan SS, Sambamoorthi U, et al. Receipt of guideline-concordant care among older women with stage I-III breast cancer: a population-based study. J Natl Compr Canc Netw. 2018;16 (6):703-710. doi:10.6004/jnccn.2018.7004

8. Carlson RW, Allred DC, Anderson BO, et al. Metastatic breast cancer, version 1.2012: featured updates to the NCCN guidelines. J Natl Compr Canc Netw. 2012;10(7):821-829. doi:10.6004/ jncen.2012.0086

9. Poorvu PD, Vaz-Luis I, Freedman RA, et al. Variation in guideline-concordant care for elderly patients with metastatic breast cancer in the United States. Breast Cancer Res Treat. 2018;168 (3):727-737. doi:10.1007/s10549-018-4659-4

10. Parisi M, Pelletier C, Cherepanov D, Broder MS. Outcomes research examining treatments, quality of life and costs in HER2-negative and triple-negative metastatic breast cancer: a systematic literature review. J Comp Eff Res. 2018;7(1):67-83. doi:10.2217/cer-2017-0027

11. Karnofsky DA, Burchernal JH. The clinical evaluation of chemotherapeutic agents in cancer. In: MacLeod CM, editor. Evaluation of Chemotherapeutic Agents. Columbia University Press; 1949:191-205.

12. American Cancer Society. Cancer facts and figures 2019. American Cancer Society, Atlanta, GA; 2019. Available from: https://www. cancer.org/content/dam/cancer-org/research/cancer-facts-andstatistics/annual-cancer-facts-and-figures/2019/cancer-facts-andfigures-2019.pdf. Accessed July 12, 2020.

13. Warren JL, Klabunde CN, Schrag D, et al. Overview of the SEER-Medicare data: content, research applications, and generalizability to the United States elderly population. Med Care. 2002;40(8 Suppl):IV-3-18.

14. National Cancer Institute, Division of Cancer Control \& Population Sciences. SEER-Medicare: about the data files. Available from: https://healthcaredelivery.cancer.gov/seermedicare/aboutdata/. Accessed March 12, 2020.

15. U.S. Health Resources and Services Administration. Bureau of health professions. Area resource file, 2009-2010 Release; 2010. Rockville, MD: US Department of Health and Human Services; Fairfax, VA: Quality Resource Systems, Inc. Codebook: HE-001(2010). Available from: https://data.hrsa.gov/topics/health-workforce/ahrf. Accessed March 25, 2021.

16. Grardishar WJ, Anderson BO, Blair SL, et al. Breast cancer version 3.2014. J Natl Compr Canc Netw. 2014;12(4):542-590. doi:10.6004/ jnccn.2014.0058

17. Thariault RL, Carlson RW, Allred C, et al. Breast cancer, version 3.2013: featured updates to the NCCN guidelines. J Natl Compr Canc Netw. 2013;11(7):753-760. doi:10.6004/jnccn.2013.0098

18. Carlson RW, Allred DC, Anderson BO, et al. Breast cancer, version 1.2010, NCCN clinical practice guidelines in oncology. Obtained from the NCCN in January 2018. Available from: www.nccn.org. Accessed March 25, 2021.

19. Carlson RW, Allred C, Anderson BO, et al. Breast cancer, version 1.2011, NCCN clinical practice guidelines in oncology. Obtained from the NCCN in January 2018. Available from: www.nccn.org. Accessed March 25, 2021.

20. Andersen R, Newman JF. Societal and individual determinants of medical care utilization in the United States. Milbank Mem Fund $Q$ Health Soc. 1973;51(1):95-124. doi:10.2307/3349613

21. Andersen RM. Revisiting the behavioral model and access to medical care: does it matter? J Health Soc Behav. 1995;36(1):1-10. doi: $10.2307 / 2137284$
22. Klabunde CN, Potosky AL, Legler JM, Warren JL. Development of a comorbidity index using physician claims data. J Clin Epidemiol. 2000;53(12):1258-1267. doi:10.1016/S0895-4356(00)00256-0

23. National cancer institute. SEER-Medicare: calculation of comorbidity weights; 2013. Available from: http://healthservices.cancer.gov/seer medicare/program/comorbidity.html.Accessed March 21, 2020.

24. Charlson ME, Pompei P, Ales KL, MacKenzie CR. A new method of classifying prognostic comorbidity in longitudinal studies: development and validation. J Chronic Dis. 1987;40(5):373-383. doi:10.1016/0021-9681(87)90171-8

25. Onukwugha E, Qi R, Jayasekera J, Zhou S. Cost prediction using a survival grouping algorithm: an application to incident prostate cancer cases. Pharmacoeconomics. 2016;34(2):207-216. doi:10.1007/s40273-015-0368-6

26. Accordino MK, Wright JD, Vasan S, et al. Use and costs of disease monitoring in women with metastatic breast cancer. J Clin Oncol. 2016;34(24):2820-2826. doi:10.1200/JCO.2016.66.6313

27. Lobbezoo DJA, van Kampen RJW, Voogd AC, et al. Prognosis of metastatic breast cancer subtypes: the hormone receptor/ HER2-positive subtype is associated with the most favorable outcome. Breast Cancer Res Treat. 2013;141(3):507-514. doi:10.1007/s10549-013-2711-y

28. Fairlie RW. An extension of the blinder-oaxaca decomposition technique to logit and probit models. J Econ Soc Meas. 2005;30 (4):305-316. doi:10.3233/JEM-2005-0259

29. Aly A, Shah R, Hill K, Botteman MF. Overall survival, costs and healthcare resource use by number of regimens received in elderly patients with newly diagnosed metastatic triple-negative breast cancer. Future Oncol. 2019;15(9):1007-1020. doi:10.2217/fon-2018-0407

30. Pal SK, Childs BH, Pegram M. Triple negative breast cancer: unmet medical needs. Breast Cancer Res Treat. 2011;125(3):627-636. doi:10.1007/s10549-010-1293-1

31. Stover DG, Winer EP. Tailoring adjuvant chemotherapy regimens for patients with triple negative breast cancer. Breast. 2015;24:S132S135. doi:10.1016/j.breast.2015.07.032

32. Palleschi M, Maltoni R, Sarti S, Melegari E, Bravaccini S, Rocca A. Immunotherapy: the end of the "dark age" for metastatic triplenegative breast cancer? Breast J. 2019. doi:10.1111/tbj.13662

33. Rakha EA, El-Sayed ME, Green AR, Lee AH, Robertson JF, Ellis IO. Prognostic markers in triple-negative breast cancer. Cancer. 2007;109 (1):25-32. doi:10.1002/cncr.22381

34. Clark O, Botrel TE, Paladini L, Ferreira MB. Targeted therapy in triple-negative metastatic breast cancer: a systematic review and meta-analysis. Core Evid. 2014;9:1-11. doi:10.2147/CE.S52197

35. Schmid P, Adams S, Rugo HS, Schneeweiss A. Impassion 130: updated overall survival (OS) from a global, randomized, double-blind, placebo-controlled, Phase III study of atezolizumab $($ atezo) + nab-paclitaxel (nP) in previously untreated locally advanced or metastatic triple-negative breast cancer (mTNBC). J Clin Oncol. 2019;37(15_suppl):1003.

36. Schmid P, Adams S, Rugo HS, Schneeweiss A. Atezolizumab and nab-paclitaxel in advanced triple-negative breast cancer. $N$ Engl J Med. 2018;379(22):2108-2121. doi:10.1056/NEJMoa1809615

37. Dent R, Trudeau M, Pritchard KI, et al. Triple-negative breast cancer: clinical features and patterns of recurrence. Clin Cancer Res. 2007;13 (15):4429-4434. doi:10.1158/1078-0432.CCR-06-3045

38. Krieger N. Overcoming the absence of socioeconomic data in medical records: validation and application of a census-based methodology. Am J Public Health. 1992;82(5):703-710. doi:10.2105/AJPH.82.5.703 


\section{Publish your work in this journal}

Breast Cancer - Targets and Therapy is an international, peer-reviewed open access journal focusing on breast cancer research, identification of therapeutic targets and the optimal use of preventative and integrated treatment interventions to achieve improved outcomes, enhanced survival and quality of life for the cancer patient.

The manuscript management system is completely online and includes a very quick and fair peer-review system, which is all easy to use. Visit $\mathrm{http}: / /$ www.dovepress.com/testimonials.php to read real quotes from published authors. 